\title{
Follow up of Patients with Eagle-Barett (Prune Belly) Syndrome Treated with Single-Stage Abdominoplasty and Total Genitourinary Tract Reconstruction
}

\section{Seguimiento de pacientes con síndrome de Eagle-Barret (prune belly) tratados con abdominoplastia en un solo tiempo y reconstrucción total del tracto genitourinario}

Nicolás Fernández ${ }^{1,2}$ Ana María Ortiz ${ }^{3}$ Juan David Iregui ${ }^{3}$ Andrea Estrada ${ }^{4}$ Angeline Rojas ${ }^{4}$ Jaime Pérez Niño ${ }^{1,3,4}$

${ }^{1}$ Division of Urology, Hospital Universitario San Ignacio, Bogotá, D.C., Colombia

${ }^{2}$ Division of Urology, Hospital por Sick Kids, University of Toronto, Toronto, ON, Canada

${ }^{3}$ Division of Urology, Pontificia Universidad Javeriana, Bogotá, D.C., Colombia

${ }^{4}$ Division of Urology, Hospital Militar Central, Universidad Militar Nueva Granada, Bogotá, D.C., Colombia

Address for correspondence Nicolás Fernández, MD, Division of Urology, Pontificia Universidad Javeriana, Carrera 7 No. 40-62, Bogotá, D.C., Colombia (e-mail: fernandez.j@javeriana.edu.co).

Urol Colomb 2020;29:14-20.

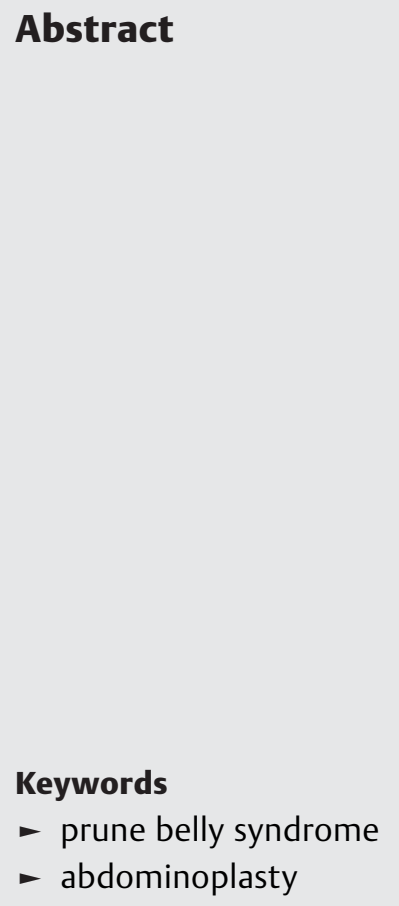

Introduction The Prune Belly Syndrome (PBS) is the deficiency or congenital hypoplasia of the abdominal muscles accompanied with disorders of the urinary tract. The surgical treatment for the uropathy of the PBS seeks to correct the anatomical defects that induce damage to the urinary tract, including the improvement of the bladder emptying. The correction of the abdominal wall defect must be considered as an important part of the treatment.

Objective To describe of the most relevant clinic characteristics and outcomes of a group of eight patients with PBS managed with abdominoplasty and reconstructive urologic surgery.

Methods Retrospective review of the medical charts of patients with PBS at Hospital Universitario San Ignacio, Hospital Militar Central of Bogotá, Clinica Infantil Colsubsidio and Fundación Oftalmológica Ardila Lulle of Bucaramanga, (Colombia) that were managed with reconstructive surgery of the urinary tract and Monfort technique abdominoplasty (between 2006 and 2016) by one of the authors (JPN). The evaluated variables included: phenotypic appearance, renal function, bowel movements, and urinary tract infection (UTI) episodes. These variables as well as the abdominal wall aspect, were evaluated postoperatively.

Results There were 11 patients identified with PBS between 2006 and 2016. Eight (8) of them underwent reconstructive urologic surgery, orchidopexy and Monfort

received

November 8, 2018

accepted

April 2, 2019
DOI https://doi.org/

$10.1055 / \mathrm{s}-0039-1688965$.

ISSN 0120-789X.

e ISSN 2027-0119.
Copyright (c) 2020, Sociedad Colombiana License terms de Urología. Publicado por Thieme Revinter Publicações Ltda., Rio de Janeiro, Brazil. Todos los derechos reservados.

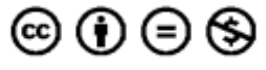




\section{Resumen}

\section{Palabras Clave \\ - síndrome de prune belly \\ - abdominoplastia}

technique abdominoplasty. After the procedures, none of the patients presented deterioration of the renal function, and they reported a better quality of the stools according to the Bristol scale; there were also less episodes of UTI. The phenotypic aspect of the abdominal wall was qualified as satisfactory in all cases.

Conclusions Reconstructive urologic surgery and abdominoplasty in patients with PBS is an excellent choice of management that reduces the number of UTIs, improves bowel movements according to the Bristol scale, and preserves the renal function. This management approach also improves the phenotypic aspect of the abdominal wall. All of this leads to higher survival rate and better quality of life.

Introducción El Síndrome de Prune Belly (SPB) es la deficiencia o hipoplasia congénita de los músculos abdominales acompañada de desórdenes del tracto genitourinario. El manejo quirúrgico de la uropatía del SPB busca corregir los defectos anatómicos que inducen daño al tracto urinario, incluyendo la mejora del vaciamiento vesical. La corrección del defecto de la pared abdominal debe considerarse como una parte importante del manejo.

Objetivos Describir las características clínicas más relevantes y el desenlace de un grupo de 8 pacientes con SPB manejados con abdominoplastia y cirugía urológica reconstructiva. Métodos Revisión retrospectiva de las historias clínicas de los pacientes con SPB del Hospital Universitario San Ignacio, Hospital Militar Central de Bogotá, Clínica Infantil Colsubsidio, y Fundación Oftalmológica Carlos Ardila Lulle de Bucaramanga (Colombia), manejados con cirugía reconstructiva de las vías urinarias y abdominoplastia tipo Monfort entre los años 2008 y 2016 por uno de los autores (JPN). Las variables incluidas fueron: aspecto fenotípico, función renal, hábito intestinal y características de las deposiciones, y episodios de infección urinaria. El desenlace de estas variables y el aspecto de la pared abdominal fueron evaluados en el postoperatorio.

Resultados se identificaron 11 pacientes con SPB entre 2006 y 2016. Ocho (8) fueron sometidos a cirugía reconstructiva de las vías urinarias, orquidopexia y abdominoplastia tipo Monfort. Después de los procedimientos, ninguno de los pacientes presentó deterioro de la función renal; los pacientes refieren mejor calidad de las deposiciones según la escala de Bristol; se presentaron menos episodios de infección de vías urinarias. El aspecto fenotípico fue calificado como satisfactorio en todos los casos.

Conclusiones La cirugía urológica reconstructiva acompañada de abdominoplastia en pacientes con SPB es una excelente forma de manejo que reduce el número de infecciones urinarias, mejora la calidad del hábito intestinal según la escala de Bristol, y conserva la función renal. Este manejo mejora además el aspecto fenotípico de la pared abdominal. Todo esto lleva a una mayor sobrevida y mejor calidad de vida.

\section{Introduction}

The Eagle-Barrett syndrome, also known as Prune Belly Syndrome (PBS), is a congenital hypoplasia and maldevelopment of the abdominal wall muscles, accompanied by disorders of the urinary tract, mainly hypotonic and dilated bladder, tortuosity and dilatation of the ureters, and bilateral cryptorchidism. This condition was initially described by Frölich in 1939, and later on named as PBS, by Osler, in 1961. ${ }^{1}$ The prevalence of this syndrome has been estimated to be 3.76 cases per 100,000 male newborns and 1.1 cases per 100,000 female newborns. ${ }^{2}$ In Colombia, the reported prevalence is 0.18 per 10,000 newborns. ${ }^{3}$ The greatest risk has been described in twins, and African Americans. ${ }^{4}$ Traditionally, infants with the most severe form of the disease have poor long-term prognosis. ${ }^{2}$ A high percentage of these infants die due to urinary sepsis or chronic renal disease. ${ }^{2,5}$ The severity of PBS can be classified into three different categories according to the Woodard classification: category 1: newborns with severe pulmonary o renal dysplasia with poor survival rates; category 2: patients with better survival rates beyond the neonatal period, with minimal or unilateral renal dysplasia and no pulmonary dysplasia; category 3 : infants with features of the anomaly that are relatively mild or incomplete and with no renal dysplasia or pulmonary hypoplasia. ${ }^{1,5}$ According to the congenital anomaly prognostic scale, patients with PBS belong to the group of anomalies with a high morbimortality, which, if not treated adequately, will lead to a significant permanent disability. ${ }^{3}$ 
Some groups have advocated a non-surgical approach unless there is a significant symptomatic compromise of the urinary tract. This approach requires a system that secures easy access to specialist for close monitoring, which may be impossible in certain countries of South America and other developing regions in the world. ${ }^{6}$ Surgical reconstruction of the urinary tract and the abdominal wall defect are complementary, and both aim to restore a functional upper tract, reducing recurrent urinary tract infections (UTIs) and renal function deterioration. Specifically, it focuses on improving bladder emptying and reducing urinary stasis and risk of infection. In selected cases, derivation with a cutaneous vesicostomy is recommended early in the neonatal period. ${ }^{7,8}$ More proximal derivations, such as cutaneous pyelostomy or ureterostomies, are useful in selected cases of pyeloureteral or vesicoureteral junction obstruction and in patients with recurrent UTIs. The correction of the abdominal wall defect must be considered as a mandatory part of the multidisciplinary approach to treat these children. It not only produces an improvement in the phenotypic appearance, but it also improves bladder, bowel and lung functionality. ${ }^{1,5}$ Orchidopexy is also part of the reconstruction. Given the complexity of care that these patients require and the significant impact that an appropriate medical treatment has on them, it is critical to understand how the postoperative outcomes are and how to improve the care of children with PBS. Long-term follow-up studies have demonstrated the need for permanent urological care, even after the initial reconstruction. ${ }^{6}$ Nonetheless, given how rare this condition is, increasing the amount of reported cases and their longterm follow-up may add more evidence to improve the care of children with PBS. We hereby present a retrospective case series describing the most relevant preoperative characteristics and outcome of patients with PBS managed with abdominoplasty and reconstructive urologic surgery, between the years 2006 and 2016.

\section{Methods}

After approval from the institutional ethics committee, a retrospective chart review was performed between 2006 and 2016. Demographic data was collected for each patient, including age at the moment of surgery and gender. Preoperative variables included a phenotypic description and clinic manifestations associated with PBS. The intraoperative variables included: the procedures performed, intraoperative complications following the Clavien-Dindo scale, and also intraoperative bleeding. ${ }^{9}$ Follow-up variables included: the renal function measured by serum creatinine comparing before and after the procedure; frequency of UTIs before and after the surgery were also included for analysis. We defined UTI as a positive urine culture with more than $100,000 \mathrm{CFU}$, associated with documented fever; bowel movement frequency and Bristol scale scores. For the surgical outcomes after abdominoplasty, the authors charted the phenotypic aspect of the abdomen as follows: 1 . Satisfactory (similar to normal aspect of the abdomen without the need for any other surgical procedures); 2. Partially satisfactory (similar to normal aspect of the abdomen with some degree of inconformity, according to the evaluators and patient/ family members, without indication of new reoperation); or 3. Unsatisfactory (no positive changes in the abdomen in which there is indication for reoperation). If there were any postoperative complications, these were also included following the Clavien-Dindo scale.

Statistical analysis was performed using SPSS software (IBM Corp. Released 2015. IBM SPSS Statistics for Windows, Version 23.0. Armonk, NY: IBM Corp). For qualitative variables, a bivariate analysis was performed. In the case of quantitative variables, measures of central tendency and dispersion measures were used.

\section{Results}

\section{Patients and Clinical Manifestations}

There were 11 male patients diagnosed with PBS between 2006 and 2016, and 8 of them were managed with abdominoplasty and reconstructive urologic surgery. Six of them were identified as type II, and 2 as type III. They were managed by only one specialist, who worked in the described hospitals or was asked to help in the management of these patients who were being managed out of Bogotá, Colombia. The mean age at the time of the surgery was of 10 years old (range: 5-21). The mean follow-up time was of 39.8 months; this long follow-up time was achieved thanks to the collaboration between the hospitals and pediatric urology services who worked together.

All patients had bilateral undescended testes and highgrade vesicoureteral reflux and classic "prune belly" phenotypic abdominal wall appearance. Other manifestations, such as megalo-urethra and mega-bladder, were present in $18.18 \%$ of the cases ( - Table $\mathbf{1}$ ).

\section{Surgical Management}

During the perinatal period, 4 (36.36\%) of the patients were managed with cutaneous vesicostomies, and 3 (27.27\%) with bilateral ureterostomies. Eight of them underwent abdominoplasty following Monfort technique, orchidopexy and reconstructive urologic surgery in a single stage, which

Table 1 Clinical manifestations of patients diagnosed with prune belly syndrome in terms of distribution and frequency

\begin{tabular}{|l|l|}
\hline Clinical presentation & $N(\%)$ \\
\hline Bilateral undescended testis & $11(100 \%)$ \\
\hline High grade vesicoureteral reflux & $11(100 \%)$ \\
\hline Agenesis of the rectus abdominis & $11(100 \%)$ \\
\hline Megalo-urethra & $2(18.18 \%)$ \\
\hline Mega-bladder & $2(18.18 \%)$ \\
\hline Urachal diverticulum & $1(9.09 \%)$ \\
\hline Patent urachus & $1(9.09 \%)$ \\
\hline Obstructive mega-ureter & $2(18.18 \%)$ \\
\hline Urethral atresia & $1(9.09 \%)$ \\
\hline
\end{tabular}


Table 2 Surgical procedures performed in patients diagnosed with prune belly syndrome in terms of distribution and frequency

\begin{tabular}{|l|l|}
\hline Surgical management & $N(\%)$ \\
\hline Reduction cystoplasty & $2(18.18 \%)$ \\
\hline Abdominoplasty with Monfort technique & $8(72.72 \%)$ \\
\hline Urethroplasty with ureteroneocystostomy & $4(36.6 \%)$ \\
\hline Urethroplasty & $2(18.18 \%)$ \\
\hline Orchidopexy: & $9(81.81 \%)$ \\
- 1 stage. & $3(50)$ \\
- 2 stages & $3(50)$ \\
- Open & $9(81.81 \%)$ \\
\hline Orchiectomy & $2(18.18 \%)$ \\
\hline Nephroureterectomy & $2(18.18 \%)$ \\
\hline Urachal diverticulectomy & $1(9.09 \%)$ \\
\hline
\end{tabular}

included some of the following procedures: reduction cystoplasty, ureteroplasty with ureteroneocystostomy, nephroureterectomy and vesical diverticulectomy in the same surgical time. Out of the 8 patients, 1 (9.09\%) presented a wound dehiscence early in the postoperative period (-Table 2 and -Figs. 1 and 2 ).

\section{Preoperative Clinical Manifestations and Postoperative Outcomes}

Only one patient required intermittent bladder catheterization during follow-up. All of the patients had spontaneous micturition with no significant residual volumes.
None of the patients with PBS presented renal function deterioration, with mean preoperative creatinine of 58.95 $\mathrm{mg} / \mathrm{dl}$ and postoperative of $62.56 \mathrm{mg} / \mathrm{dl}$ after abdominoplasty and reconstructive urologic surgery (-Table 3 ).

Preoperative bowel movements were Bristol 3 in 50\% of the patients, followed by Bristol 2 in 33.3\%. In the postoperative follow-up, 5 (83.3\%) of the patients presented an improvement to Bristol scale of 4 (-Table 4 ).

Four (36.6\%) of the patients presented more than 2 febrile UTIs before the surgery. In patients that underwent surgery, $6(54.54 \%)$ did not present any new episodes of UTI and 2 (18.18\%) presented 1 episode of UTI after surgery, during follow-up (-Table 5).

When comparing the episodes of UTI, the mean preoperative episodes were twice more frequent (2.5) than postoperative episodes (0.16).

Regarding the evaluation of the phenotypic and aesthetic aspect of the abdominal wall after abdominoplasty, every case was classified as satisfactory by the evaluators (-Fig. $\mathbf{3}$ ).

\section{Discusion}

Prune belly syndrome is a disorder that includes complex malformations with different degrees of severity and great variation in its clinical presentation, which is why the treatment given to each patient is not homogeneous. The presence of severe renal dysfunction and pulmonary hypoplasia in PBS are predictors of mortality, which is close to $100 \%$ in the first days of life in category I patients. ${ }^{1}$ The prognosis of these patients depends on the degree of urinary stasis or obstruction, as well as on the presence of UTIs. ${ }^{1,2,10}$

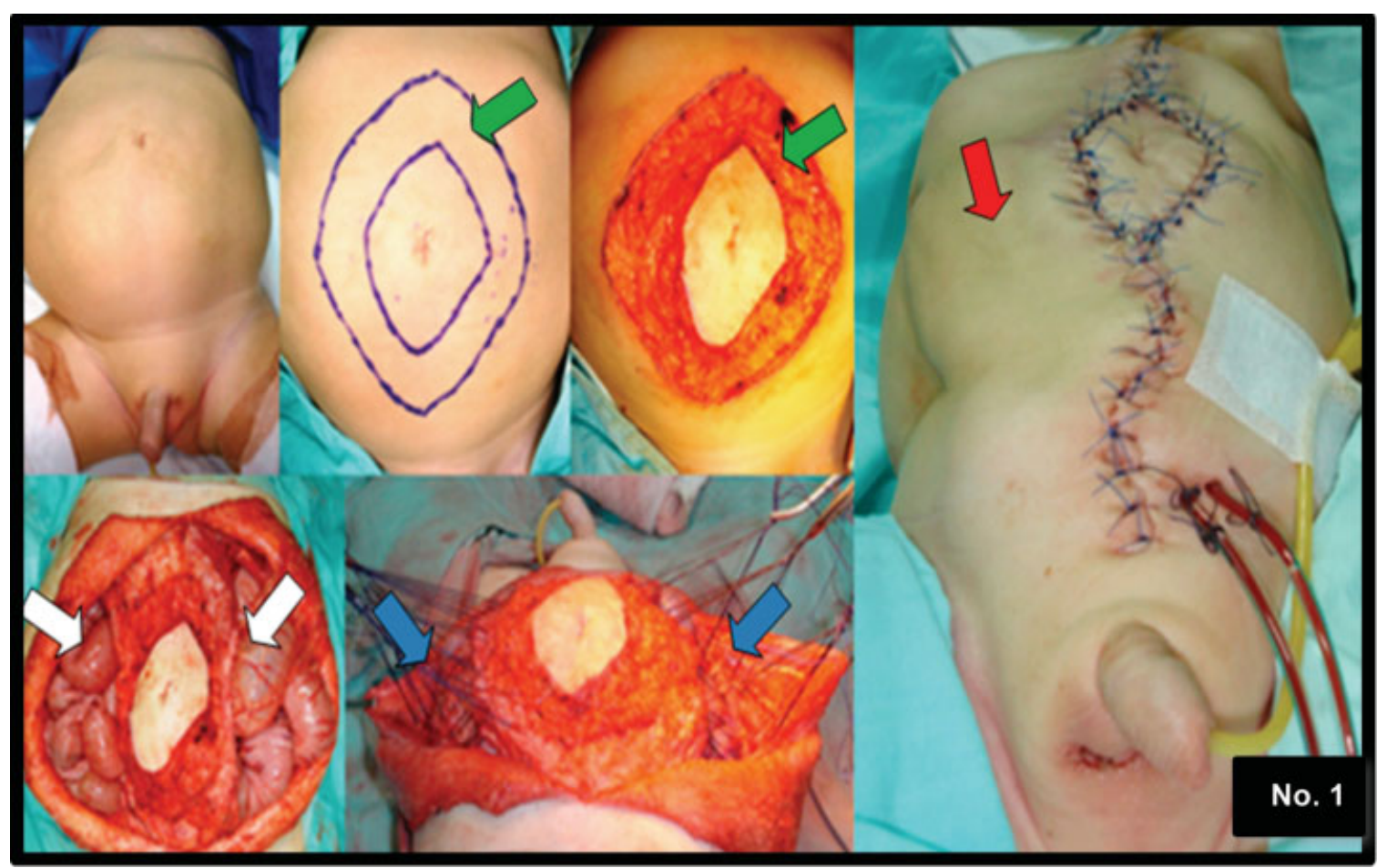

Fig. 1 Abdominoplasty with Monfort technique. Green arrow: elliptic incision in the midline with umbilical island preservation. White arrow: abdominal approach respecting the insertion of the rectus abdominis muscle. Blue arrow: Advancement and plication of the lateral fascia over the midline. Red arrow: final result. 


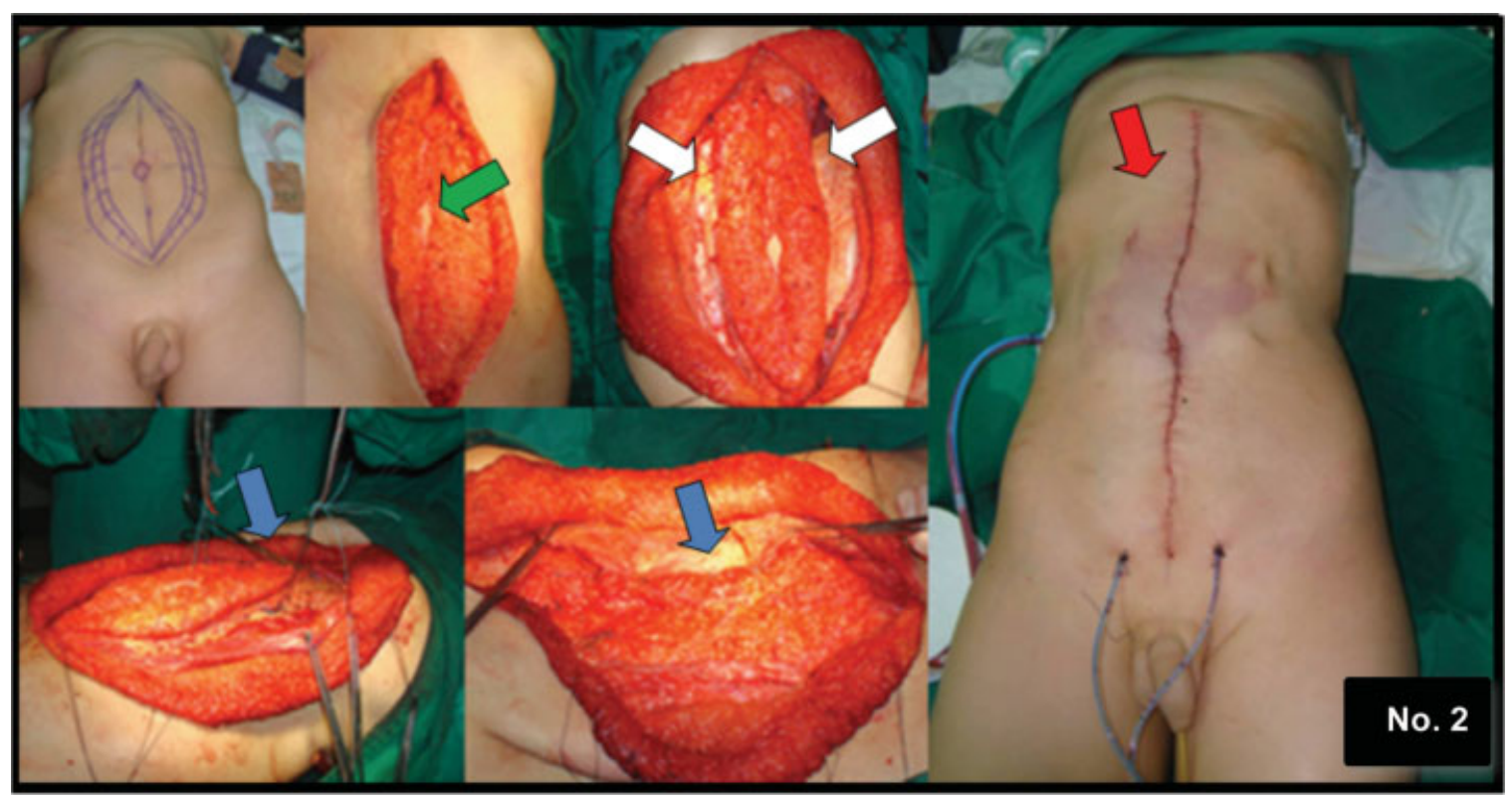

Fig. 2 Abdominoplasty with Monfort technique. Green arrow: elliptic incision in the midline with umbilical island preservation. White arrow: abdominal approach respecting the insertion of the rectus abdominis muscle. Blue arrow: Advancement and plication of the lateral fascia over the midline. Red arrow: final result.

Table 3 Evaluation of pre and postoperative creatinine depuration

\begin{tabular}{|l|l|l|l|l|}
\hline Variable & Mean & ST & Minimum & Maximum \\
\hline $\begin{array}{l}\text { Preoperative } \\
\text { creatinine } \\
\text { (ml/dl) }\end{array}$ & 58.95 & 21.78 & 38.4 & 98 \\
\hline $\begin{array}{l}\text { Postoperative } \\
\text { creatinine } \\
\text { (ml/dl) }\end{array}$ & 62.56 & 24.71 & 37.6 & 107 \\
\hline
\end{tabular}

Abbreviation: ST, standard deviation.

Table 4 Evaluation of pre and postoperative Bristol scale bowel movements

\begin{tabular}{|l|l|}
\hline Preoperative Bristol & Frequency \% \\
\hline 2 & $2(33.3)$ \\
\hline 3 & $3(50)$ \\
\hline 4 & $1(16.6)$ \\
\hline Total & $6(100)$ \\
\hline Postoperative Bristol & Frequency \\
\hline 3 & $1(16.6)$ \\
\hline 4 & $5(83.3)$ \\
\hline Total & $6(100)$ \\
\hline
\end{tabular}

It is important to recognize that UTI and progressive renal disease are factors that affect the quality of life and survival rate in PBS. Early interventions with procedures such as ureterostomy or cutaneous vesicostomies allow to differ the abdominoplasty and the urologic reconstructive surgery, until the right age is reached and pulmonary maturation is completed. ${ }^{1,5}$
Table 5 Pre and postoperative urinary tract infection episodes in terms of distribution and frequency

\begin{tabular}{|l|l|}
\hline Pre UTI & $N(\%)$ \\
\hline 0 & $2(18.18 \%)$ \\
\hline 2 & $1(9.09 \%)$ \\
\hline 3 & $1(9.09 \%)$ \\
\hline 4 & $1(9.09 \%)$ \\
\hline 6 & $1(9.09 \%)$ \\
\hline Total & $8(100 \%)$ \\
\hline Post UTI & $N(\%)$ \\
\hline 0 & $5(83.3)$ \\
\hline 2 & $2(18.18 \%)$ \\
\hline Total & $8(100)$ \\
\hline
\end{tabular}

Abbreviation: UTI, urinary tract infection.

The muscle deficit in PBS leads to functional alterations in valsalva maneuvers, such as coughing and pushing, which negatively influences in the bowel and bladder function, as well as an adequate postural balance during physical activity. ${ }^{11}$

Abdominoplasty is an intervention that favors the correction of these factors, and also allows an adequate exposure for the reconstructive urologic surgery as well as benefiting the final phenotypic and aesthetic aspect of the abdominal wall. ${ }^{11-13}$ Conservative management options with limited surgical interventions and the use of external supporting mechanisms, such as corsets, are an alternative for some authors. ${ }^{10,14}$

Some modifications have been described for the conventional techniques of abdominoplasty, with the creation of a new belly button at the height of the iliac crests with better aesthetic results. Patients managed with the Monfort original technique had a superior belly button location, unlike the 


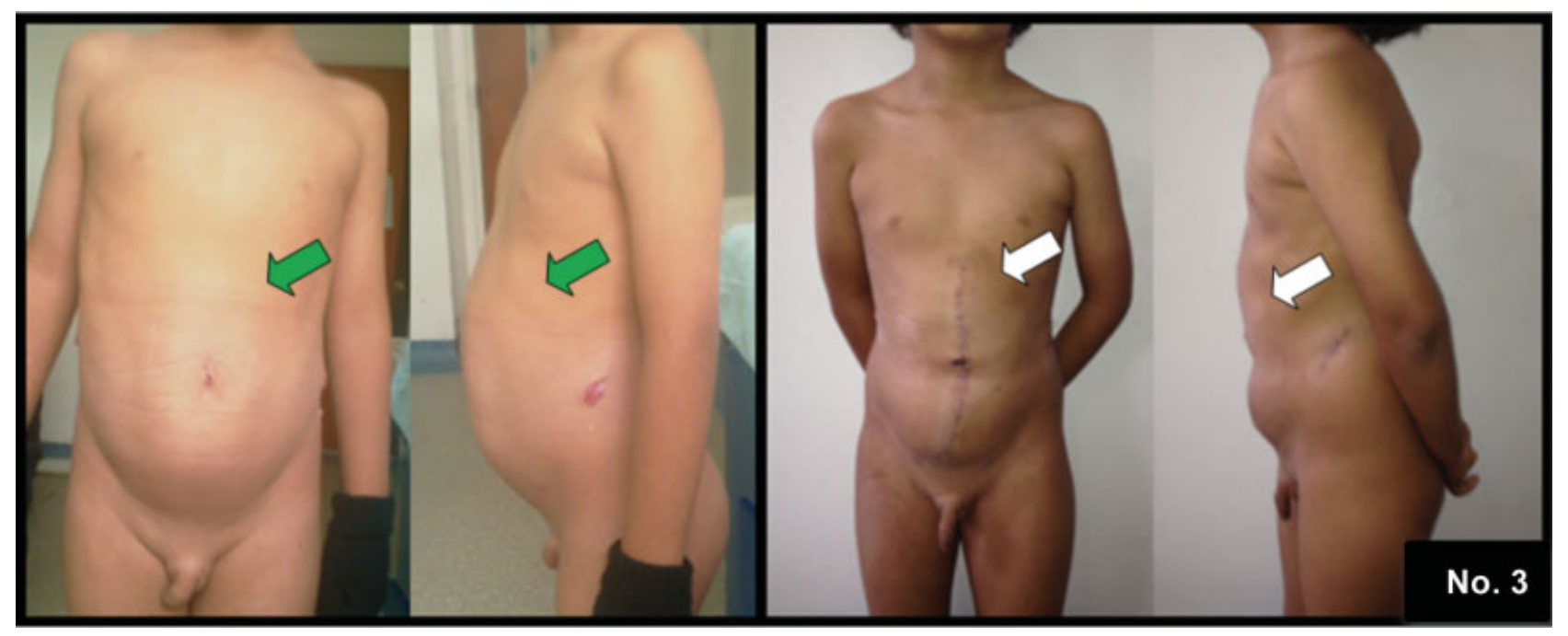

Fig. 3 Preoperative and postoperative aspect of the abdominal wall in a patient with abdominoplasty. Green arrow: preoperative. White arrow: postoperative

usual location. ${ }^{12}$ Our management proposal includes the adequate position of the belly button. Femoral flaps have also been used. ${ }^{11-13}$

Fishman et al describes laparoscopic abdominoplasty in patients with incomplete PBS, in which there is no association with urinary tract malformations. In these cases, the pneumoperitoneum allows to clearly identify the abdominal defect and, later on, to realize a vertical or horizontal plication with excision of the redundant skin by an ellipsoidal incision. ${ }^{15}$

Other retrospective series have shown the benefits of reconstructive urologic surgery associated with abdominoplasty in the preservation of renal function. Vahudin Zugor et al evaluates the long-term results of 16 patients with PBS, recollected over 36 years, mentioning the stability of the renal function after surgical management; nonetheless, the treatment was not homogeneous for all cases, and only $25 \%$ were managed with abdominoplasty. ${ }^{16}$ Likewise, Denés et al retrospectively evaluated 32 cases between 1985 and 2002, all managed with reconstructive urologic surgery, orchidopexy, and simultaneous abdominoplasty. The renal function was compared before and after the surgery, with serum ureic nitrogen levels and creatinine, finding that the renal function was stable or improved in 30 patients. ${ }^{10}$ In the present series, the renal function was evaluated with calculated creatinine depuration, without deterioration of it in any of the cases. A mean postoperative creatinine depuration of $62.56 \mathrm{ml} / \mathrm{min}$ was found, which increased compared with the preoperative creatinine depuration ( $58.95 \mathrm{ml} / \mathrm{min}$ ).

The bowel habit has been evaluated in some of the works; nonetheless, they lack an objective qualification. Smith et al documented changes in the bowel function of patients managed with Monfort abdominoplasty and concomitant urinary reconstruction, with satisfactory findings in the urinary continence in 7 patients, improvement in urinary flow in 10 patients and defecation in 5 patients. ${ }^{17}$ In our series, it was possible to compare the change in the quality of the stools identifying objectively an improvement. Lesavoy et al informs an improvement in constipation in $71 \%$ of patients after reconstructive surgery of the abdominal wall, with a follow up time of 20 years. ${ }^{13}$

Smith et al also documented a significant decrease in the incidence of UTIs, with a preoperative average of 5.7 and a postoperative average of 1.2 episodes of UTIs in the 1 st year after the surgery. ${ }^{13}$ In the same way, we observed that the mean number of UTIs that occur preoperatively is greater when compared to those that occur postoperatively (2.5 vs 0.16 ).

Denés et al and Malcom A. Lesavoy, have described the phenotypic and aesthetic benefits of the abdominoplasty in patients with PBS. ${ }^{10,13}$ In our series, we describe the results of the abdominoplasty as satisfactory for all the cases, when compared with the preoperative phenotypic and aesthetic aspects. There was a low percentage of postoperative complications, the majority of them originated in areas of skin suture and due to necrosis or superinfection with abscess formation. ${ }^{13}$ In our study, only one of the patients presented an early postoperative complication, due to partial epidermolysis and wound dehiscence.

It is worth mentioning that, given the great diversity in the clinical presentation of this pathology, the performed surgical procedures differ in significant ways among the cases and force the physician to individualize the diagnosis and therapeutic approach for each patient. ${ }^{11}$ Also, given the low prevalence of the disease, the number of patients involved in our series and in the reported ones in literature is low, and, so, it does not allow to extrapolate the results to the general population.

There are few data about long-term follow-up of patients classified as category II. The probable variation in the classification of the disease's gravity in treatment groups, and the variation in the natural evolution of the disease make it difficult to compare retrospective studies.

The controversy with category II patients will continue until there is a standard medical and surgical approach based on individual clinical features. ${ }^{1}$ Nonetheless, we can say that, in experimented hands, it is possible to obtain satisfactory results with extensive reconstructive surgery in older toddlers and kids. 


\section{Conclusion}

Reconstructive urologic surgery accompanied by abdominoplasty in patients with PBS could reduce the episodes of UTIs, constipation, and preserve the renal function. The cosmetic benefits of abdominoplasty are evident in all patients.

Conflicts of Interest

The authors have no conflicts of interest to declare.

\section{References}

1 Hassett S, Smith GHH, Holland AJA. Prune belly syndrome. Pediatr Surg Int 2012;28(03):219-228

2 Routh JC, Huang L, Retik AB, Nelson CP. Contemporary epidemiology and characterization of newborn males with prune belly syndrome. Urology 2010;76(01):44-48. Doi: 10.1016/j.urology 2009.12.072

3 Zarante I, Franco L, López C, Fernández N. Frecuencia de malformaciones congénitas: evaluación y pronóstico de 52.744 nacimientos en tres ciudades colombianas. Biomedica 2010;30(01): 65-71

4 Ramasamy R, Haviland M, Woodard JR, Barone JG. Patterns of inheritance in familial prune belly syndrome. Urology 2005;65 (06):1227http://linkinghub.elsevier.com/retrieve/pii/S009042950 4015249

5 Caldamone A, Woodard J. Prune Belly Syndrome. In: Campbell's urology. 10th ed. Elsevier; 2011

6 Lopes RI, Tavares A, Srougi M, Dénes FT. 27 years of experience with the comprehensive surgical treatment of prune belly syndrome. J Pediatr Urol 2015;11(05):276.e1-276.e7
7 Chen IL, Huang HC, Lee SY, et al. Urachal catheter provides new choice for long-term urinary diversion in prune belly syndrome. Urology 2011;77(02):466-468. Doi: 10.1016/j.urology.2010.05.028

8 Pérez J, Llinás E, Figueroa VH. Vesicostomía cutánea en la población pediátrica. Urol Colomb 2007;XVI(01):93-98. Available from: http://www.redalyc.org/html/1491/149120468013/index.html

9 Dindo D, Demartines N, Clavien P-A. Classification of surgical complications: a new proposal with evaluation in a cohort of 6336 patients and results of a survey. Ann Surg 2004;240(02):205-213

10 Dénes FT, Arap MA, Giron AM, Silva FAQ Arap S. Comprehensive surgical treatment of prune belly syndrome: 17 years' experience with 32 patients. Urology 2004;64(04):789-793, discussion 793-794

11 Fearon JA, Varkarakis G. Dynamic abdominoplasty for the treatment of prune belly syndrome. Plast Reconstr Surg 2012;130(03): 648-657

12 Bukowski TP, Smith CA. Monfort abdominoplasty with neoumbilical modification. J Urol 2000;164(05):1711-1713

13 Lesavoy MA, Chang EI, Suliman A, Taylor J, Kim SE, Ehrlich RM. Longterm follow-up of total abdominal wall reconstruction for prune belly syndrome. Plast Reconstr Surg 2012;129(01):104e-109e

14 Tank ES, McCoy G. Limited surgical intervention in the prune belly syndrome. J Pediatr Surg 1983;18(06):688-691

15 Fishman AI, Franco I. Laparoscopic-assisted surgical reconstruction of a rare congenital abdominal wall defect in two children misdiagnosed with prune-belly syndrome. J Pediatr Urol 2013;9 (04):448-452

16 Zugor V, Schott GE, Labanaris AP. The Prune Belly syndrome: urological aspects and long-term outcomes of a rare disease. Pediatr Rep 2012;4(02):e20

17 Smith CA, Smith EA, Parrott TS, Broecker BH, Woodard JR. Voiding function in patients with the prune-belly syndrome after Monfort abdominoplasty. J Urol 1998;159(05):1675-1679 